\title{
The Coat Protein Is Required for the Elicitation of the Capsicum L' Gene-Mediated Resistance Against the Tobamoviruses
}

\author{
A. de la Cruz, L. López, F. Tenllado, J.R. Díaz-Ruíz, A.I. Sanz, C. Vaquero, M.T. Serra, and I. García- \\ Luque \\ Departamento de Biología de Plantas, Centro de Investigaciones Biológicas (CSIC), Velázquez 144, 28006- \\ Madrid, Spain \\ Received 10 July 1995. Accepted 8 November 1996.
}

In Capsicum, the resistance against tobamoviruses conferred by the $L^{2}$ gene is effective against all but one of the known tobamoviruses. Pepper mild mottle virus (PMMoV) is the only virus which escapes its action. To identify the viral factors affecting induction of the hypersensitive reaction (HR) mediated by the Capsicum $\mathrm{spp} . \mathrm{L}^{2}$ resistance gene, we have constructed chimeric viral genomes between paprika mild mottle virus (PaMMV) (a virus able to induce the HR) and PMMoV. A hybrid virus with the PaMMV coat protein gene substituted in the PMMoV-S sequences was able to elicit the HR in Capsicum frutescens $\left(\mathrm{L}^{2} \mathrm{~L}^{2}\right)$ plants. These data indicate that the sequences that affect induction of the HR mediated by the $L^{2}$ resistance gene reside in the coat protein gene. Furthermore, a mutant that codes for a truncated coat protein was able to systemically spread in these plants. Thus, the elicitation of the host response requires the coat protein and not the RNA.

Additional keywords: tobamovirus $\mathrm{L}^{2}$ resistance gene.

Tobamoviruses are one of the most destructive pathogens of pepper crops. In Capsicum, resistance against tobamoviruses is characterized by induction of a hypersensitive reaction (HR), manifested by the appearance of necrotic local lesions at the site of infection. So far, four seemingly allelic resistance genes $\left(\mathrm{L}^{1}-\mathrm{L}^{4}\right)$ of increased effectiveness at the $\mathrm{L}$ locus (Boukema et al. 1980, 1982) have been identified. The viral strains eliciting the $\mathrm{HR}$ in $\mathrm{L}^{3}$-pepper plants also elicit the HR in $\mathrm{L}^{4}$-pepper plants; strains inducing the $\mathrm{HR}$ in $\mathrm{L}^{2}$-pepper plants, induce the $\mathrm{HR}$ in both $\mathrm{L}^{3}$ and $\mathrm{L}^{4}$ plants; and the ones that elicit the $\mathrm{HR}$ in $\mathrm{L}^{1}$-pepper plants elicit the $\mathrm{HR}$ in $\mathrm{L}^{2}, \mathrm{~L}^{3}$, and $\mathrm{L}^{4}$ plants (Boukema 1982).

It is known that the initial recognition of pathogen elicitors by the product of the host resistance genes is a key feature that mediates both the specificity and the outcome of the host defense response (reviewed in Keen 1992). We have recently

Corresponding author: I. García-Luque; Fax:34-1-562 7518

This article is in the public domain and not copyrightable. It may be freely reprinted with customary crediting of the source. The American Phytopathological Society, 1997. identified the tobamoviral coat protein as the inducer of the Capsicum $\mathrm{L}^{3}$ gene-mediated resistance. In addition, we showed that a single amino acid substitution in the coat protein is sufficient to change the phenotype of chimeric viruses from virulent to avirulent (Berzal-Herranz et al. 1995). To extend our studies on the Capsicum $\mathrm{L}$ gene-mediated resistance, we have analyzed here the viral factors inducing the resistance conferred by the $\mathrm{L}^{2}$ gene. This gene, initially named the $\mathrm{L}$ gene (Boukema et al. 1980) was the first plant resistance gene ever identified as a single dominant "Mendelian character" (Holmes 1934). $\mathrm{L}^{2}$ has been found to be present in certain varieties of Capsicum frutescens, such as Tabasco and minimum, being active against all pepper infecting tobamoviruses, with the exception of pepper mild mottle virus (PMMoV). $\mathrm{L}^{2}$ gene-mediated resistance is manifested through the formation of small necrotic local lesions (NLL).

To identify the viral determinants involved in the elicitation of the $\mathrm{L}^{2}$ gene mediated resistance, we have constructed chimeric viruses between the S strain of PMMoV (Wetter et al. 1984; Alonso et al. 1989) and paprika mild mottle virus (PaMMV) (Rast 1977; García-Luque et al. 1993). PMMoV-S overcomes the resistance conferred by $\mathrm{L}^{2}$, and infects these plants in a generalized fashion producing symptoms of mosaic; while PaMMV elicits the $\mathrm{HR}$ in $\mathrm{L}^{2}$ pepper plants. Both viruses belong to the so-called pepper strains of the tobamoviruses, that do not replicate in tomato plants and accumulate to only a low level in some Nicotiana species.

The results presented here show that the coat protein gene of PaMMV acts as avirulence factor of the $\mathrm{L}^{2}$ gene-mediated resistance. Mutations in the coat protein gene leading to the synthesis of a truncated coat protein reveal that a functional coat protein and not the RNA is responsible for the induction of the host response.

\section{RESULTS}

The viral determinants for inducing the $\mathrm{L}^{2}$ gene-mediated hypersensitive reaction map to the coat protein gene.

As an initial step to localize the PaMMV sequences involved in the induction of the $\mathrm{L}^{2}$ gene-mediated hypersensitive reaction, a hybrid virus genome, THG-1, was created. THG-1 contains the 5'-proximal 5348 nt of PMMoV-S fused to the 3'-terminal $1146 \mathrm{nt}$ of PaMMV. The PaMMV region 
corresponds to the $\mathrm{C}$-terminal part of the $30 \mathrm{~K}$ gene, the coat protein $(\mathrm{CP})$ gene and the $3^{\prime}$ noncoding region. In addition, this genomic region contains the promoter elements for the $\mathrm{CP}$ subgenomic mRNA and minus-strand RNA synthesis (reviewed in Dawson 1992).

THG-1 hybrid genome (Fig. 1) was constructed at the cDNA level by replacing in the full-length cDNA clone pTS the PMMoV-S sequences extending from nucleotide 5348 to 6357 with the corresponding region of PaMMV. A conserved NcoI restriction site in the cDNA sequences of both viruses (nucleotide position 5348 in the PMMoV-S RNA sequence determined in Alonso et al. 1991) was utilized to prepare the hybrid cDNA. The pTHG-1 plasmid was digested with XbaI and transcribed with T7 RNA polymerase. Capped in vitro
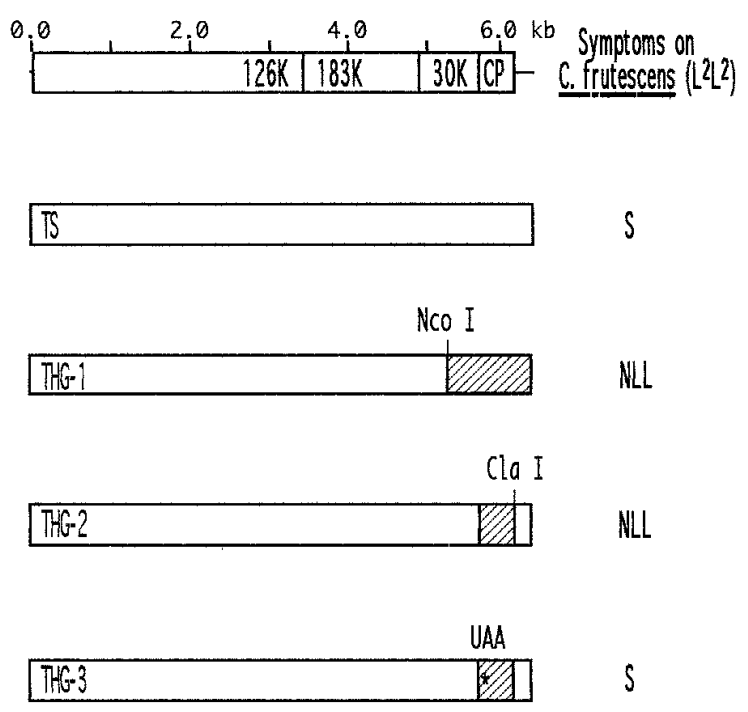

Fig. 1. Pathogenicity of hybrid viruses comprised of sequences derived from PaMMV and PMMoV-S. Open boxes represent PMMoV sequences. Stippled boxes represent sequences from PaMMV. Relevant restriction sites used for constructing the hybrid genomes are indicated. UAA, stop codon introduced into the PaMMV coat protein gene. The symptoms induced in Capsicum frutescens L. var. Tabasco plants are described at the right of each construct. S, systemic infection. NLL, necrotic local lesions. A schematic diagram of the tobamoviral genomic organization is shown on top of the diagram. The regions coding for the $126 \mathrm{~K}$ and $183 \mathrm{~K}$ proteins which are part of the polymerase complex, the $30 \mathrm{~K}$ protein responsible for the cell-to-cell viral movement and the coat protein are indicated. transcripts were characterized by inoculation in N. tabacum L. cv. Xanthi nc, $N$. benthamiana Domin. and C. frutescens cv. Tabasco.

Inoculation of THG-1 transcripts in Xanthi nc tobacco produced small necrotic lesions at 2 to 3 days postinoculation (d.p.i.) in all of the inoculated leaves. The lesions were undistinguishable, both in size and appearance rate, from the lesions formed after the infection by PMMoV-S. In contrast to this result, the infection by PaMMV induced formation of visible NLL only in the old leaves of the plant.

In tobacco, the THG-1 transcripts infectivity was about $50 \%$ lower than that of the pTS-derived transcripts, as measured by the number of NLL produced in each half-leaf after inoculating with similar amounts of each transcript. The reduced infectivity of the THG-1 transcripts could not be ascribed to the few additional nucleotides of plasmid origin present in the transcripts (5'-CAGAGATC in THG-1, and 5'CGCG in PMMoV-S), since the number of NLL induced by the chimeric THG-1 virus were also lower when purified virions were used as source of inocula (data not shown). The data thus indicate that in this particular hybrid viral construct, the sequences of PMMoV and PaMMV are not fully compatible. A partly functional THG-1 hybrid $30 \mathrm{~K}$ protein, or a reduced efficiency of the PMMoV-S-encoded viral polymerase to recognize the PaMMV RNA promoter elements present in the substituted region could account for the observed THG-1 virus diminished infectivity. In $N$. benthamiana, THG-1 virus produced symptoms of leaf curling and stunting at 12 to 15 d.p.i., similar to the symptoms displayed by PMMoV-S-infected plants. These symptoms differed from the PaMMV-induced yellowing of the infected leaves (data not shown).

In Tabasco pepper $\left(\mathrm{L}^{2} \mathrm{~L}^{2}\right)$ plants, the in vitro synthesized transcripts from pTHG-1 produced NLL at 3-4 d.p.i. (Fig. 1). The lesions were similar to the ones observed after the inoculation with the parental PaMMV, and distinct from the PMMoV-S induced symptoms of leaf curling and bright mosaic (Figs. 1 and 2B). By RT-PCR and ELISA assays, neither THG-1 nor PaMMV could be detected in the upper noninoculated leaves, thus confirming that the hybrid virus was localized to the inoculated leaves (data not shown).

Viral RNA was extracted from virions purified from systemically infected $N$. benthamiana plants and the identity of the viral progeny was tested by RT-PCR, using a pair of primers (corresponding to nucleotide positions 4834 to 4851 and 6321 to 6334 in the PMMoV-S RNA genome) covering the hybrid junction in THG-1. As illustrated in Figure $3 \mathrm{~A}$, the HindIII restriction pattern of the cDNA products obtained in
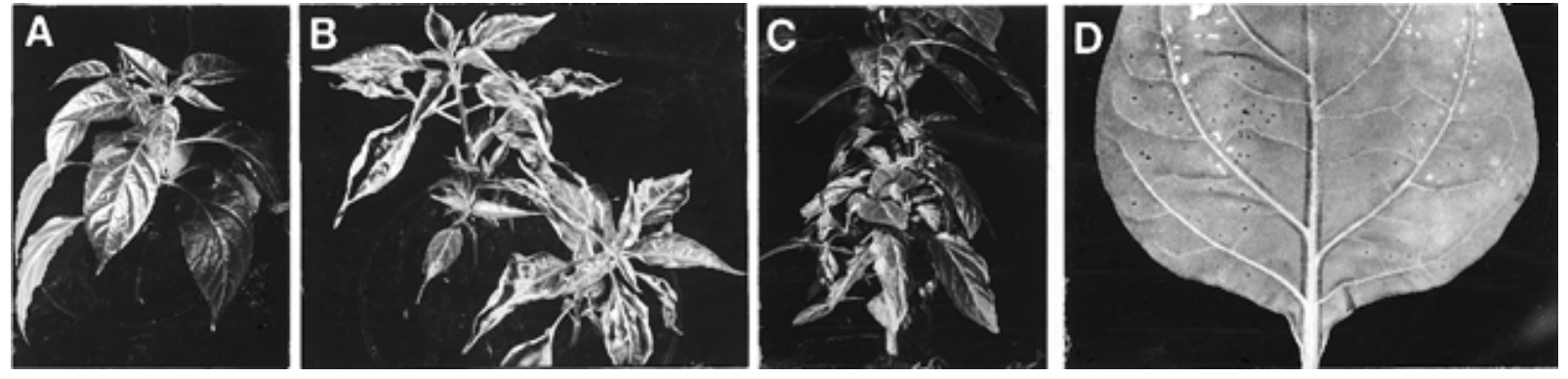

Fig. 2. Symptomatology of Capsicum frutescens cv. Tabasco $\left(\mathrm{L}^{2} \mathrm{~L}^{2}\right)$ plants inoculated with PMMoV-S (B), THG-3 (C), PaMMV (D, left half), and THG3 (D, right half). A, Control mock-inoculated plant. 
the amplification of the THG-1 viral progeny was identical to the pattern obtained with the parental transcription clone pTHG-1. The observed HindIII restriction fragments were distinct from those resultant from the amplification of both PaMMV and PMMoV-S RNAs. In all cases, the restriction fragments corresponded to the sizes predicted from the nucleotide sequence.

Additionally, immunological assays were carried out to corroborate the coat protein identity of the chimeric THG-1 virus by using specific anti-PaMMV and anti-PMMoV-S sera, that discriminate PaMMV CP from PMMoV-S CP. Both assays: ELISA tests of the infected tissue and Western blot analysis of purified virus particles confirmed that the coat protein of THG-1 hybrid virus corresponded to that of PaMMV (data not shown).

These results indicate that the viral region responsible for the Capsicum $\mathrm{L}^{2}$ gene-mediated localization of PaMMV maps to the last $1000 \mathrm{nt}$ of the genome.

We have previously described that the tobamoviral coat protein gene is involved in the elicitation of the Capsicum $\mathrm{L}^{3}$ gene-mediated resistance (Berzal-Herranz et al. 1995). Since both Capsicum $\mathrm{L}^{2}$ and $\mathrm{L}^{3}$ resistance genes are likely alleles (Boukema et al. 1980), we considered the possibility that the coat protein was also involved in the Capsicum $\mathrm{L}^{2}$ genemediated host response. To test this possibility a chimeric genome, THG-2, was constructed (Figs. 1 and 4), to allow the exact substitution of the PMMoV-S coat protein gene by the corresponding PaMMV region. Since the $30 \mathrm{~K}$ and CP ORFs do not overlap in the genomes of PaMMV and PMMoV-S, it was possible to manipulate their sequences such that the resultant THG-2 virus would not contain PaMMV sequences other than the coat protein coding region.

In vitro synthesized THG-2 transcripts were directly inoculated onto Tabasco pepper $\left(\mathrm{L}^{2} \mathrm{~L}^{2}\right)$ plants. At 3 to 4 d.p.i., NLL

A

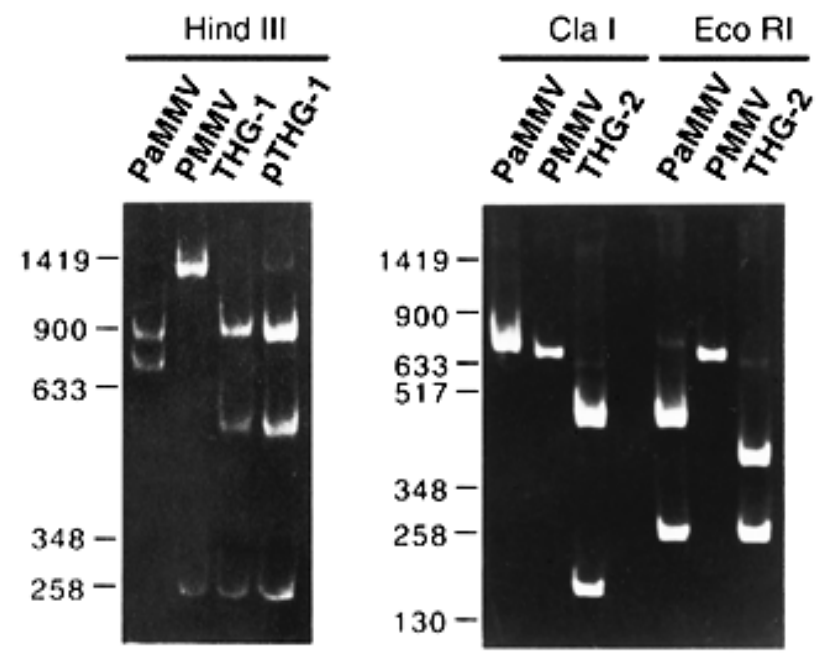

Fig. 3. PCR analysis of progeny virion RNAs. cDNA to purified THG-1, THG-2, PaMMV, or PMMoV was synthesized and PCR amplified as described under Materials and Methods. The amplified cDNA products were digested with the restriction enzymes shown on top of the figure. The pTHG-1 lane corresponds to the PCR amplification product of the template plasmid. Numbers on the left show the migration of selected bands from pUC18 digested with SauIIIA and HinfI used as size standards. appeared that were indistinguishable from those induced by PaMMV (Figs. 1 and 2). In addition, no virus could be detected by RT-PCR or ELISA analysis of the upper noninoculated leaves of the infected plants (data not shown). To confirm the identity of the THG-2 viral progeny, single Tabasco NLLs were transferred to $N$. benthamiana plants and after two subsequent passages in this host, virion RNA was extracted from the systemically infected plants. The THG-2 viral RNA was analyzed by RT-PCR amplification and restriction of a cDNA fragment spanning the coat protein gene and the 3 '-noncoding region, as described in Materials and Methods. The ClaI digestion of the amplified cDNA products yielded two fragments of 499 and $175 \mathrm{bp}$ from the THG-2 cDNA, leaving uncut the PaMMV and PMMoV-S amplified cDNA products (Fig. 3B). Similarly, EcoRI digestion of the amplified cDNA products yielded the fragments expected from the nucleotide sequences of each virus: 492 and $273 \mathrm{bp}$ in PaMMV, and 401 and 273 bp in THG-2 (Fig. 3B). Western blot analysis of purified virion particles and ELISA test of the infected tissues also showed that THG-2 virus contained the PaMMV CP (data not shown).

These results reveal that the substitution of the PaMMV coat protein gene into the PMMoV-S genome makes that the resistance-breaking PMMoV-S virus becomes localized by the action of the $\mathrm{L}^{2}$ gene.

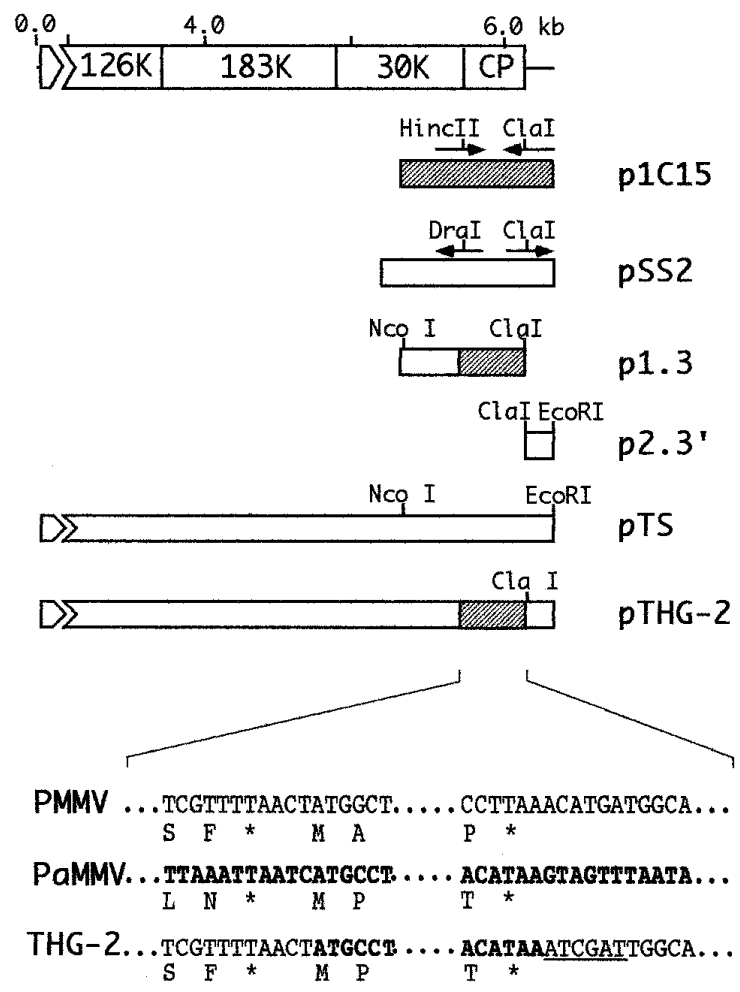

Fig. 4. Schematic representation of the THG-2 genome organization. Open boxes denote the open reading frames, and horizontal lines represent the noncoding sequences. Open boxes correspond to PMMoV-S sequences. Stippled boxes correspond to PaMMV sequences. The nucleotide sequences and deduced amino acid sequences surrounding the coat protein gene in PMMoV-S, PaMMV (bold face), and THG-2 hybrid genomes are shown. The Cla I restriction sites used for constructing the hybrid genome is underlined. 
Elicitation of the HR is influenced by the coat protein.

To determine if the ability of the PaMMV CP to induce the $\mathrm{L}^{2}$ gene-mediated HR resides either in the coat protein or in the RNA itself, a chimeric mutant THG-3 with a frameshift mutation in the coat protein gene was constructed (Fig. 1). Thus, insertion of 4 bp 75 nt downstream of the AUG initiation codon of the PaMMV CP ORF produces a translation frameshift. The putative protein product would be 34 aa long instead of the 161-aa long polypeptide codified by the PaMMV CP ORF comprising the $26 \mathrm{~N}$-terminal amino acids of PaMMV CP and 8 non-PaMMV amino acids at its $\mathrm{C}$ terminus.

The in vitro transcripts generated from the THG-3 plasmids were inoculated directly into $N$. tabacum Xanthi nc and Tabasco pepper plants. In Xanthi nc tobacco, THG-3 mutant induced NLL. However, no NLL were visualized in the inoculated Tabasco pepper leaves. By 15 d.p.i., the THG-3inoculated Tabasco pepper plants showed an increase of the number of axillary buds relative to the mock-inoculated control plants (Fig. 2C). During the 2-mo period in which plants were inspected, no other visible symptoms were observed. No virion particles were detected when leaf dip preparations were examined by electron microscopy, nor could the viral coat protein be detected in the upper noninoculated leaves extracts by Western blot analysis (data not shown). However, the viral RNA was detected in both inoculated and upper noninoculated leaves at 17 d.p.i. by RT-PCR performed on total RNA (see Materials and Methods).

Nucleotide sequence analysis of the amplified cDNA fragment spanning the coat protein gene showed that the progeny RNA maintained the introduced mutation and there were no other nucleotide changes in this region. These data confirmed that the frameshift coat protein mutant had spread systemically in this host.

To determine the rate of the systemic spread of the coat protein mutant THG-3 vs. PMMoV-S in Tabasco plants, plants were inoculated with total leaf RNA extracted from either THG-3- or PMMVoS- systemically infected-Tabasco and the presence of the virus was assayed at different d.p.i. by backinoculation onto Xanthi nc tobacco plants. At 4 d.p.i., NLL were produced after the inoculation of tobacco with sap from either the inoculated or upper noninoculated PMMoV-S infected Tabasco leaves as well as from THG-3 inoculated leaves. The number of NLL induced by THG-3-infected tissue was lower (about 30\%) than the ones induced by PMMoV-S. No NLL were visible in tobacco plants when the THG-3upper noninoculated leaves were used as inoculum. At 7 d.p.i., the inoculation of sap from both THG-3-inoculated and upper noninoculated Tabasco leaves into tobacco produced NLL, showing that the spread of the coat protein mutant is reduced with respect to $\mathrm{PMMoV}-\mathrm{S}$.

Thus, we conclude that the RNA molecule itself is not responsible for the induction of the $\mathrm{L}^{2}$ gene-mediated $\mathrm{HR}$ and therefore, the PaMMV coat protein is required for the elicitation of $\mathrm{HR}$ and restriction of viral spread in $\mathrm{L}^{2}$ pepper plants.

\section{DISCUSSION}

The construction of chimeric viruses THG-1 and THG-2, containing sequences derived from PMMoV-S and PaMMV, has allowed us to determine that the PaMMV information re- quired for the localization of the viral infection mediated by the pepper $\mathrm{L}^{2}$ resistance gene is located within the coat protein gene. The fact that the chimeric mutant THG-3 which codes for a truncated coat protein was able to infect Tabasco $\left(\mathrm{L}^{2} \mathrm{~L}^{2}\right)$ pepper systemically excludes the possibility that the RNA molecule itself is the active viral factor involved in the elicitation of the HR, and confirms that the PaMMV coat protein is the avirulence factor of the Capsicum $\mathrm{L}^{2}$ gene-mediated resistance. Moreover the resistance $\mathrm{L}^{2}$-breaking property of this defective THG-3 isolate shows that the resistance requires production of a virus-encoded protein. That is that resistance breaking is not the result of the supression of preexisting defense mechanism(s). Instead, it is avirulence which is the positive viral function. This situation is consistent with resistance as manifestation of recognition of the viral elicitor by a host receptor (reviewed in Fraser 1990; Culver et al. 1991; Keen 1992; Staskawicz et al. 1995). Clearly, from the data presented here, the PaMMV CP is a good candidate for being the elicitor molecule of $\mathrm{L}^{2}$ resistance.

The finding that the tobamoviral coat protein acts as the avr factor for both Capsicum $\mathrm{L}^{2}$ and $\mathrm{L}^{3}$ resistance genes is well in accordance with the genetic work earlier presented by Boukema (1982) in the sense that both genes are alleles of the L locus, although at present the possibility cannot be excluded that they could be closely linked genes.

Since all the tobamoviruses that elicit the $\mathrm{L}^{2}$ gene-mediated $\mathrm{HR}$ also elicit the HR in $\mathrm{L}^{3}$ plants, whereas PMMoV elicit the resistance conferred by the $\mathrm{L}^{3}$ gene but overcomes the $\mathrm{L}^{2}$ gene-mediated resistance, it might be possible that the $\mathrm{L}$ resistance genes against the tobamoviruses in Capsicum have evolved to recognize a wider spectrum of tobamoviral coat proteins. A similar situation has been described for the Nicotiana $\mathrm{N}^{\prime}$ gene-mediated resistance, able to recognize most of the tobamoviral coat proteins (Culver and Dawson 1991). The phenomenon that the coat protein acts as elicitor of the defense response in different plant genera such as Nicotiana and Capsicum, and possibly in other host systems (Dawson et al. 1988) might indicate the high degree of conservation of plant disease resistance genes, such that the same pathogen avr factor is functional in widely separated host genera (Whalen et al. 1988; Valent et al. 1991; Goulden and Baulcombe 1993).

It is at present unknown which part of the tobamoviral coat protein is involved in the recognition event that triggers the defense response. It could be either the entire coat protein or part of it. However, in both Nicotiana $\mathrm{N}^{\prime}$ and Capsicum $\mathrm{L}^{3}$ gene-mediated resistances, amino acid substitutions that modify the overall coat protein configuration have been implicated in the observed changes in the pathogen virulence towards the host (Dawson et al. 1988; Saito et al. 1989; Culver et al. 1994; Berzal-Herranz et al. 1995). Accordingly, and due to the ability of the $\mathrm{L}^{2}$ pepper plants to recognize all but one of the pepper-infecting tobamoviruses, it is possible that several coat protein structural or conformational configurations might be recognized in this host and that subtle changes that alter the configuration of the protein, such as those previously described (Culver and Dawson 1989b; Culver et al. 1994; Berzal-Herranz et al. 1995), make PMMoV to escape the $\mathrm{L}^{2}$ gene action.

The ability of the THG-3 mutant coding for a truncated coat protein to induce in Tabasco pepper plants symptoms that were different from those observed in PMMoV-S-infected 
plants (Fig. 2C and B) indicates that the coat protein modulates symptom expression in this particular host-virus system, as described for other host-virus combinations such as alfalfa mosaic virus-tobacco (Neeleman et al. 1991), cucumber mosaic virus-tobacco (Shintaku et al. 1992), and tobacco mosaic virus-tobacco (Dawson et al. 1988; Banerjee et al. 1995). In contrast, the tobamoviral coat protein does not modify the symptomatology in either Nicotiana sylvestris (Culver and Dawson 1989a) or Capsicum chinense plants (Berzal-Herranz et al. 1995), thus indicating that the effect of the viral coat protein on symptom expression depends specifically upon the host-pathogen interaction.

\section{MATERIALS AND METHODS}

\section{Viral sources, purification, and RNA extraction.}

The origin of PMMoV-S (pathotype $\mathrm{P}_{1,2}$ ) has been reported (Alonso et al. 1989). PaMMV (pathotype $\mathrm{P}_{1}$ ) corresponds to a Dutch isolate from pepper described as tobamovirus isolate P11, and lately renamed PaMMV (Rast 1977; García-Luque et al. 1993). Viruses were purified and viral RNAs were extracted as described (Alonso et al. 1991; and García-Luque et al. 1990).

\section{Construction of hybrid viral genomes.}

The production of the full-length PMMoV-S cDNA transcription clone pTS and its derivative pTHI-8 was previously described (Berzal-Herranz et al. 1995). The nucleotide numbering is that of Alonso et al. (1991).

DNA templates for different hybrid genomes were constructed by substituting the PMMoV-S sequences contained in plasmid pTS, with the correspondent of PaMMV. Recombinant constructs were tested by restriction enzyme analysis and partial DNA sequencing.

Two PaMMV cDNA clones: p1C15, spanning from nucleotides 24 to 1137 from the $3^{\prime}$-end, and p1C3 containing the $3^{\prime}$ terminal 887 nucleotides (García-Luque et al. 1993) were used to construct the intermediate PaMMV plasmid p1.915. This clone contains the 3'-terminal 1146 nucleotides and it was obtained by inserting the 476-bp SmaI-BglII fragment from plasmid p1C15 into the HindIII-blunt-BglII sites of plasmid p1C3. Hybrid genome THG-1 was created by cloning the 1154 bp NcoI/XbaI-blunt fragment from plasmid p1.915 into NcoI/EcoRI-blunt-digested plasmid pTS.

To construct pTHG-2, the nucleotide sequences surrounding the coat protein gene in both PMMoV-S and PaMMV were mutagenized by PCR. The borders of the PaMMV coat protein gene were modified by using as template plasmid p1C15 and the mutagenic oligonucleotides $1 \mathrm{CPI}$ and $1 \mathrm{CPF}$ as $5^{\prime}$ and $3^{\prime}$ primers. Oligonucleotide 1CPI (5'-GACTAGTTAACTATGCCTTATACTGT), corresponds to the first $14 \mathrm{nt}$ of the coat protein gene (underlined) with an added HindII recognition site (bold). Oligonucleotide 1CPF (5'-TGCATGCATTTACTTATTAAATCGA TTATGT) is complementary to PaMMV nucleotide positions 272 to 287 from the $3^{\prime}$ end, in which an internal ClaI restriction site (bold) was located next to the TAA coat protein stop codon (underlined).

The nucleotide sequences upstream the coat protein gene in PMMoV-S were mutagenized on plasmid pSS2, spanning from nucleotide 5187-6357 in the PMMoV-S RNA genome (Berzal-Herranz et al. 1995); by using as $5^{\prime}$ and $3^{\prime}$ primers the universal M13/pUC reverse sequencing primer, and the oligonucleotide 5'-CCAAGCTTTAAAACGAAGAAGACTC complementary to PMMoV-S nucleotide 5665 to 5682 (underlined), to which a DraI restriction site (boldface) was added. The amplified product was doubly restricted with StyI and DraI, and the 332-bp fragment was gel purified and ligated to the 507-bp HincII-NsiI fragment obtained after the mutagenic PCR amplification and restriction of the PaMMV coat protein gene, above described. Both fragments were cloned together into the StyI-PstI digested pT3T7 plasmid, generating clone p1.3.

The coat protein gene $3^{\prime}$ downstream sequences in the PMMoV-S genome were also modified by PCR using as template plasmid pSS-2, and the oligonucleotides: 5'-CGAATTCAATCGATTGGCATAAATAAGTTGAACGA, corresponding to PMMoV nucleotide positions 6165 to 6185 (underlined) in which a ClaI (boldface) plus an EcoRI restriction sites were incorporated, and the universal M13/pUC direct sequencing primer as $5^{\prime}$ and $3^{\prime}$ primers, respectively. The amplified PCR product was restricted with EcoRI, and the 278-bp fragment was cloned into the EcoRI site of plasmid pT3T7BM. After corroborating the nucleotide sequence, the 270-bp ClaI-EcoRI fragment of the resultant plasmid p2-3' was ligated to the 823-bp NcoI-ClaI fragment from plasmid p1.3 and both together to plasmid pTS restricted with NcoI and EcoRI, producing hybrid genome pTHG-2.

The frameshift coat protein mutant was obtained by filling the protruding termini of the unique $B g l \mathrm{II}$ site of clone p1.3. After digestion with $K p n I$ and NcoI, both fragments: the 415bp NcoI-BglII-blunt and the 455-bp BglII-blunt-KpnI were cloned into the Nco and KpnI sites of plasmid pT3T7BM, resulting in plasmid $\mathrm{pBg} 7$. After corroborating that the plasmid had the desired 4-bp insertion, the 831-bp NcoI-ClaI fragment was cloned along with the 270-bp ClaI-EcoRI fragment from plasmid p2-3' into the $\mathrm{NcoI}$ and EcoRI sites of plasmid pTS, resulting in template pTHG-3.

\section{In vitro synthesis and plant propagation of viral RNA genomes.}

Genomic RNAs were synthesized by in vitro transcription of recombinants with T7 RNA polymerase, once they were digested with either $X b a \mathrm{I}$ (pTHG-1) or MluI (pTS, pTHG-2, or pTHG-3), and propagated directly in Nicotiana tabacum L. Xanthi nc, Capsicum frutescens $\mathrm{L}$. cv Tabasco $\left(\mathrm{L}^{2} \mathrm{~L}^{2}\right)$ and Nicotiana benthamiana Domin. plants, as previously described (Berzal-Herranz et al. 1995).

Single necrotic local lesions from Tabasco pepper plants inoculated with either THG-1 or THG-2 transcripts were used to inoculate $N$. benthamiana plants to analyze the viral progeny from purified virions.

Infectivity assays of Tabasco pepper plants inoculated with the different viral RNA genomes were carried out in Xanthi nc tobacco plants using sap or total leaf RNA extract as source of inocula. Total leaf RNA was extracted according to Logemann et al. (1987).

\section{Analysis of viral progenies.}

The viral progenies derived from the infectious transcripts were analyzed by reverse transcriptase-PCR followed by restriction enzyme digestion, as described (Tenllado et al. 1994). The use of oligonucleotides 5'-GGTTCGTTTGTTTATAGA 
(corresponding to nucleotide positions 4834 to 4851 of PMMoV-S RNA), and 5'-GGGGATTCGAACCC, (complementary to nucleotide 6321 to 6334) allows the RT-PCR amplification of a 1501-bp DNA fragment, when using PMMoV-S RNA as template; 1644 DNA bp fragment when using PaMMV RNA, and $1637 \mathrm{bp}$ in the case of hybrid virus THG-1. Digestion of the amplified products with HindIII restriction enzyme was used to identify the three viral RNAs.

By using the oligonucleotides 1CPI and 5'GGGGATTCGAACCC (complementary to PMMoV-S nucleotide 6321 to 6334) in RT-PCR, it was possible to amplify DNA fragments of 765,662 , and 674 bp corresponding to the viral RNAs from PaMMV, PMMoV-S, and THG-2, respectively. Digestion of the amplified fragments with $C l a \mathrm{I}$ and EcoRI was used to discriminate hybrid virus THG-2 from PaMMV and PMMoV-S. The ClaI restriction site was introduced during the construction of hybrid template pTHG-2, and the EcoRI restriction site is present in the PaMMV coat protein gene $516 \mathrm{nt}$ from the $3^{\prime}$ end.

The progeny viral RNA from the mutant coding for a truncated coat protein was analyzed by nucleic acid sequencing through the modified region. Nucleotide sequence was determined on RT-PCR amplified fragments, by using the femtomol sequencing kit (Promega). cDNA was synthesized on total leaf RNA using oligonucleotides $1 \mathrm{CPI}$ and $1 \mathrm{CPF}$ as primers.

The coat proteins of purified virions were analyzed by Western blot, using specific PaMMV and PMMoV-S antisera, as described in Berzal-Herranz et al. (1995). Virion particles (10 ng) were heated at $100^{\circ} \mathrm{C}$ for $2 \mathrm{~min}$ in SDS-PAGE sample buffer $(100 \mathrm{mM}$ Tris- $\mathrm{HCl} \mathrm{pH}$ 6.8, 2\% SDS, $100 \mathrm{mM}$ dithiothreitol, $10 \%$ glycerol, $0.01 \%$ Bromphenol blue) and resolved in the discontinuous SDS-PAGE system (Laemmli 1970). The production of the rabbit anti-PaMMV and anti-PMMoV-S sera have been previously reported (Tenllado et al. 1995; Alonso et al. 1991).

\section{Virus detection by RT-PCR and ELISA.}

The detection of viral sequences in plants was carried out by RT-PCR on total leaf RNA. cDNA was synthesized using oligonucleotides $1 \mathrm{CPI}$ and $1 \mathrm{CPF}$ as primers.

The detection and quantification of viral coat proteins in plant extracts by double antibody sandwich enzyme-linked immunosorbent assay (DAS-ELISA) were carried out as described (Berzal-Herranz et al. 1995).

\section{ACKNOWLEDGMENTS}

We thank J. Guijarro for photographic work. The work was supported by grants from the CICYT (AGF94-0364; AGF95-0696) and the EC (BRIDGE program no. BIOCT90-0156).

\section{LITERATURE CITED}

Alonso, E., García-Luque, I., Avila-Rincón, M. J., Wicke, B., Serra, M. T., and Díaz-Ruiz, J. R. 1989. A tobamovirus causing heavy losses in protected pepper crops in Spain. J. Phytopathol. 125:67-76.

Alonso, E., García-Luque, I., de la Cruz, A., Wicke, B., Avila-Rincón, M. J., Serra, M. T., Castresana, C., and Díaz-Ruíz, J. R. 1991. Nucleotide sequence of the genomic RNA of pepper mild mottle virus, a resistance-breaking tobamovirus in pepper. J. Gen. Virol. 72:28752884.

Banerjee, N., Wang, J. Y., and Zaitlin, M. 1995. A single nucleotide change in the coat protein gene of tobacco mosaic virus is involved in the induction of severe chlorosis. Virology 207:234-239.

Berzal-Herranz, A., de la Cruz, A., Tenllado, F., Díaz-Ruíz, J. R., López, L., Sanz, A. I., Vaquero, C., Serra, M. T., and García-Luque, I. 1995. The Capsicum $\mathrm{L}^{3}$ gene-mediated resistance against the tobamoviruses is elicited by the coat protein. Virology 209:498-505.

Boukema, I. W. 1982. Resistance to TMV in Capsicum chacoense Hunz. is governed by an allele of the L-locus. Capsicum Newsl. 3:4748.

Boukema, I. W. 1980. Allelism of genes controlling resistance to TMV in Capsicum L. Euphytica 29:433-439.

Culver, J. N., and Dawson, W. O. 1989a. Tobacco mosaic virus coat protein: An elicitor of the hypersensitive reaction but not required for the development of mosaic symptoms in Nicotiana sylvestris. Virology 173:755-758.

Culver, J. N., and Dawson, W. O. 1989b. Point mutations in the coat protein gene of tobacco mosaic virus induce hypersensitivity in Nicotiana sylvestris. Mol. Plant-Microbe Interact. 2:209-213.

Culver, J. N., and Dawson, W. O. 1991. Tobacco mosaic virus elicitor coat protein genes produce a hypersensitive phenotype in transgenic Nicotiana sylvestris plants. Mol. Plant-Microbe Interact. 4:458-463.

Culver, J. N., Lindbeck, A. G. C., and Dawson, W. O. 1991. Virus-host interactions: Induction of chlorotic and necrotic responses in plants by tobamoviruses. Annu. Rev. Phytopathol. 29:193-217.

Culver, J. N., Stubbs, G., and Dawson, W. O. 1994. Structure-function relationship between tobacco mosaic virus coat protein and hypersensitivity in Nicotiana sylvestris. J. Mol. Biol. 242:130-138.

Dawson, W. O. 1992. Tobamovirus-Plant Interactions. Virology 186:359-367.

Dawson, W. O., Bubrick, P., and Grantham, G. L. 1988. Modifications of the tobacco mosaic virus coat protein gene affect replication, movement and symptomatology. Phytopathology 78:783-789.

Fraser, R. S. S. 1990. The genetics of resistance to plant viruses. Annu. Rev. Phytopathol. 28:179-200.

García-Luque, I., Serra, M. T., Alonso, E., Wicke, B., Ferrero, M. L., and Díaz-Ruiz, J. R. 1990. Characterization of a Spanish strain of pepper mild mottle virus (PMMV-S) and its relation to other tobamoviruses. J. Phytopathol. 129:1-8.

García-Luque, I., Ferrero, M. L., Rodríguez, J. M., Alonso, E., de la Cruz, A., Sanz, A. I., Vaquero, C., Serra, M. T., and Díaz-Ruiz, J. R. 1993. The nucleotide sequence of the coat protein genes and 3' noncoding regions of two resistance-breaking tobamoviruses in pepper shows that they are different viruses. Arch. Virol. 131:75-88.

Goulden, M. G., and Baulcombe, D. C. 1993. Functionally homologous host components recognize potato virus $\mathrm{X}$ in Gomphrena globosa and potato. Plant Cell 5:921-930.

Holmes, F. O. 1934. Inheritance of ability to localize tobacco mosaic virus. Phytopathology 24:984-1002.

Keen, N. T. 1992. The molecular biology of disease resistance. Plant Mol. Biol. 19:109-122.

Laemmli, U. K. 1970. Cleavage of structural proteins during the assembly of the head of bacteriophage T4. Nature 227:680-685.

Logemann, J., Schell, J., and Willmitzer, L. 1987. Improved method for the isolation of RNA from plant tissues. Analytical Biochem. 163:1620.

Neeleman, L., van der Kuyl, A. C., and Bol, J. 1991. Role of alfalfa mosaic virus coat protein gene in symptom formation. Virology 181:687693.

Rast, A. T. B. 1977. Introductory remarks on strain of TMV infecting peppers in the Netherlands. Pages 83-84 in: Comptes rendues du 3me Congrés Eucarpia sur la Genetique et la selection du Piment. Monfavet/Avignon.

Saito, T., Yamanaka, K., Watanabe, Y., Takamatsu, N., Meshi, T., and Okada, Y. 1989. Mutational analysis of the coat protein gene of tobacco mosaic virus in relation to hypersensitive response in tobacco plants with the $\mathrm{N}^{\prime}$ gene. Virology 173:11-20.

Shintaku, M. H., Zhang, L., and Palukaitis, P. 1992. A single amino acid substitution in the coat protein of cucumber mosaic virus induces chlorosis in tobacco. Plant Cell 4:751-757.

Staskawicz, B. J., Ausubel, F. M., Baker, B. J., Ellis, J. G., and Jones, J. D. G. 1995. Molecular genetics of plant disease resistance. Science 268:661-667.

Tenllado, F., García-Luque, I., Serra, M. T., and Díaz-Ruíz, J. R. 1994. Rapid detection and differentiation of tobamoviruses infecting L- 
resistant genotypes of pepper by RT-PCR and restriction analysis. J. Virol. Methods 47:165-174.

Tenllado, F., García-Luque, I., Serra, M. T., and Díaz-Ruíz, J. R. 1995. Nicotiana benthamiana plants transformed with the $54 \mathrm{kDa}$ region of the pepper mild mottle tobamovirus replicase gene exhibit two types of resistance responses against viral infection. Virology 211:170-183.

Valent, B., Farrall, L., and Chumley, F. G. 1991. Magnaporthe grisea genes for pathogenicity and virulence identified through a series of backcrosses. Genetics 127:87-101.

Wetter, C., Conti, M., Altschuh, D., Tabillion, R., and van Regenmortel, M. H. V. 1984. Pepper mild mottle virus, a tobamovirus infecting pepper cultivars in Sicily. Phytopathology 74:405-410.

Whalen, M. C., Stall, R. E., and Staskawicz, B. J. 1988. Characterization of a gene from a tomato pathogen determining hypersensitive reaction in non-host species and genetic analysis of this resistance in bean Proc. Natl. Acad. Sci. 85:6743-6747. 